\title{
Analysis on the Influence of Electronic Currency Circulation on Central Bank
}

\author{
Yutong Zhang \\ University of California, School of Social Sciences, Irvine, United States, 92697 \\ Corresponding author. Email: zytramsey@gmail.com
}

\begin{abstract}
In the contemporary world, the rise of electronic money has attracted many people's concern. The applicability and efficiency of using electronic money have become the reasons why people love to use it. But electronic money also has a certain impact on the central bank. This paper analyzes the challenge of electronic money to the central bank from the perspective of the monopoly of electronic money on the central bank's currency distribution rights and its impact on the stability of the central bank. Meanwhile, this article also analyzes the impact of electronic money on the central bank's monetary policy including money supply, circulation speed and introduces some feasible solutions in the end.
\end{abstract}

Keywords: Electronic money, the central bank, monetary policy

\section{INTRODUCTION}

In recent years, Electronic money(e-money) has quickly become a powerful emerging force in the monetary system and even the financial system. Electronic money was originally conceived by an American computer scientist named David Chaum. He invented an encrypted digital blind signature, and the anonymous money is the predecessor prototype of electronic money. However, the past few years, electronic money has encountered many controversies and oppositions. For instance, the development and popularization of electronic money may bring impact on the role of the central bank or even bring negative effect. Electronic money may be used for money laundering and some illegal transactions. In this paper, the definition of electronic money and how the emergence of electronic money will impact the Central bank in multiple ways will be discussed. Besides, what methods can people use to mitigate or avoid the impact of electronic money on the central bank will also be mentioned.

\section{THE DEFINITION OF ELECTRONIC MONEY}

Electronic money transaction also called e-money is a new accounting system and method in recent years. Users can exchange cash or assets for the same amount of data or virtual currency from the issuer of electronic money. According to European Central Bank[1], "Electronic money (e-money) is broadly defined as an electronic store of monetary value on a technical device that may be widely used for making payments to entities other than the e-money issuer." Essentially, electronic money replaces cash transactions with electronic bookkeeping. Therefore, electronic money can be regarded as a currency without physical form based on informatization and computer calculation. The following figure is the process of the transaction of e-money. 


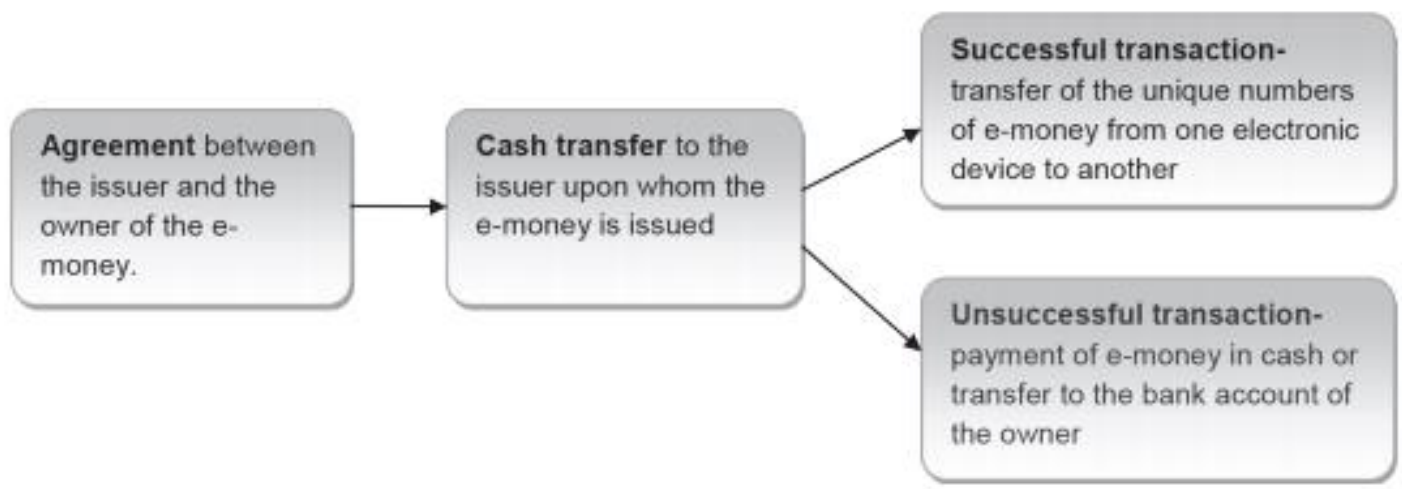

Figure 1 The process of the transaction of e-money [2]

\section{THE TYPES OF ELECTRONIC MONEY}

Broadly speaking, electronic currencies include digital currencies (Bitcoin, Litecoin), but also virtual currencies, cryptocurrencies, and virtual wallets that people spend on the Internet. In summary, electronic money can be divided into the following two forms.

\subsection{Account Dependent Electronic Money}

Account-dependent electronic money is used when people use specific accounts as carriers. To count currency, electronic payment settlements can only flow in different accounts. The owners of these electronic currencies cannot freely use or control these currencies. They must complete the settlement or purchase and sale with the help of the account manager. The transaction process of this type of electronic currency is very similar to the transfer between ordinary bank accounts. Firstly, the transferor sends the transfer instruction through the Internet or ATM machine. Then the electronic money management company will verify the request, if it is valid, it will be transferred to the account of the transferee. However, the difference is that electronic money management companies do not require the participation of banks, and some third-party financial companies can also play this role.

\subsection{Cash-Based Electronic Money}

Contrary to account-dependent electronic money, cash-based electronic money does not rely on accounts for transactions, people only need to pay it like cash.
Cash electronic money includes IC card as the carrier currency and online cash currency. IC card type electronic money is directly used and traded by the card owner without transferring money through a third party. And online electronic currency is a digital currency published on the Internet like Bitcoin. It is a series of digitized information, arranged according to certain digital strings rules. In order not to be easily copied by others, they will use a special password for encryption, that is, cryptocurrency.

\section{THE CHARACTERISTICS OF THE ELECTRONIC MONEY}

\subsection{The Applicability of Electronic Money}

A significant feature of electronic money is its applicability. This applicability reflects two aspects, one is that it can be used on many occasions, and the other is that electronic money is very convenient to use. According to Abrazhevich [3],"The suitability of debit cards (bank cards) and credit cards is quite high, while cheques are no longer commonly used in several European countries." (85) Obviously, Electronic money has been widely used in many countries. The data from the Bank of International Settlement shows that as early as 2001, the number of global electronic money systems reached 49, and by 2003 it had increased to 94.[4] Also, usability is a significant property of e-money, that is one of the reasons why e-money has become a trend gradually. All payments are automated, forming an efficient payment process. The figure shows that the value of money transactions in the EU area. 


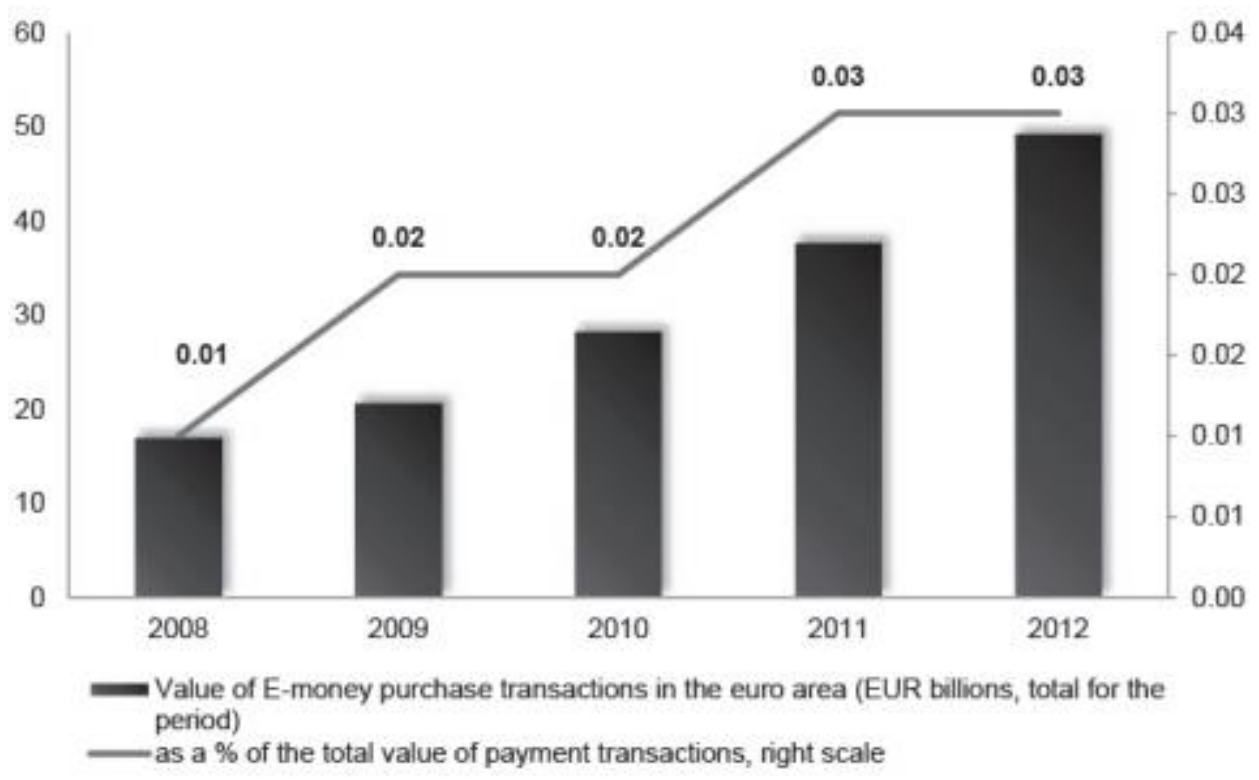

Figure 2 Value of e-money transactions in the euro area[2]

\subsection{The efficiency of electronic money}

With the widespread use of electronic money, transaction costs decrease and become more efficient. Both the issuance and management of cash and transactions require labor force cost. As Abrazhevich issued that [3], "There are lots of discussions on the ability of payment systems to accept "micropayments". Small-amount payments are amounts less than a \$1; micropayments are less than several cents. Systems should be able to receive small payments without performance degradation and posing high costs of transactions. The cost of per transaction should be reasonable for processing small amounts"(86) In addition, the electronic currency is convenient for trial use and has strong adaptability, which also improves the efficiency of the entire financial industry.

\section{THE DISCUSSION}

\subsection{The Impacts of Electronic Money on Central Bank}

5.1.1. The monopoly power of the central bank in the issue of money and the authority of the distribution rights

In general, the currency of each country is issued and managed by the central bank of that country. Therefore, the National Central Bank has the monopoly right to issue currency of the country, and the monopoly power of the central bank plays an essential role in the financial system of the country. Firstly, the central bank controls the country's base currency, and this has a great effect on both long-term and short-term interest rates. The emergence and popularity of electronic money will impact the monopoly position of the central bank. At present, a large part of the electronic currency issuers in the market are some commercial banks and other financial institutions, and uncontrolled issuance of currency will lead to disorder of the entire country's economic system. Secondly, the central bank needs strong technical and financial support to monopolize the issuance of electronic money. Since electronic money is based on information and computers, it needs to have strong technology to continuously innovate to meet the diversity of electronic money. If the central bank monopolizing without considering thoroughly, it will adversely affect the country's electronic money. In conclusion, since the conditions for the central bank to monopolize electronic currency are not yet mature, electronic currency is bound to have a certain degree of impact on the central bank's currency issuance monopoly.

\subsubsection{The influence and challenge of electronic money on central banks stability}

In the process of making monetary policy, the independence of the central bank is an indispensable condition. Since different countries have different economic development conditions (developed countries and developing countries), each country will also adopt different monetary policies. However, the electronic currency trading market and trading platform is a very open model, and all transactions are not limited to regions and time. The platform can transfer a large sum of money from the northern hemisphere to the southern hemisphere in a short time. If electronic money does not have a mature regulatory system, this large-scale transaction will cause some financial fluctuations and thus affect the independence of the central bank. 


\subsubsection{The Influence of electronic money on central bank seigniorage}

Maintaining a balance of payments is very important for operating reasonably and efficiently for a country's central bank. In addition to relying on national legal guarantees, the seigniorage is a core part of the central bank's revenue. According to the WH Buiter [5], "Seigniorage refers historically, in a world with commodity money, to the difference between the face value of a coin and its costs of production and mintage." Obviously if electronic money is widely developed and popularized, the demand for cash will be greatly reduced resulting in a reduction in seigniorage revenue. Once the economic source of most of the central banks is reduced, the central bank will try to make up for this gap from other channels, which will further affect the effectiveness of the country's monetary policy and the independence of the central bank mentioned above. For example, according to BIS (Bank for International Settlements, which is an international organization dedicated to international monetary and fiscal policy cooperation), if France's mint tax revenue decreases by more than $54 \%$, the central bank must rely on other economic sources.

\subsection{The Impact of Electronic Money on National Monetary Policy}

Essentially, the currency is an agreement between the sellers and buyers. The initial form of currency was shells and stones and then it evolved into gold and eventually into the paper money and electronic money that we use today. Driven by the e-finance of finance, the development of electronic money has made traditional currency changed the definition of currency. The European Central Bank stated the impact of the emergence of electronic money on monetary policy: " Firstly, there is a need to safeguard the role of money as the unit of account for economic transactions. Secondly, the effectiveness of monetary policy instruments might be affected by the widespread adoption of electronic money. Thirdly, the emergence of electronic money might have repercussions on the information content of monetary indicator variables with regard to the primary objective of price stability."[6]

\subsubsection{The central bank may lose control of the money supply}

According to Popovska-Kamnar, Neda [2], " Decreasing the central bank's control of money supply depends on the degree of substitution of currency in circulation with e-money. The currency in circulation is part of monetary aggregates, and if it is decreased as a result of wider use of e-money, it will produce difficulties in the measurement of monetary aggregates and of the control of money supply by the central bank." The money supply is determined by the money multiplier as the

$$
\mathrm{m}=\frac{\text { MoneyStock }}{\text { MonetaryBase }}=\frac{\text { Deposists }+ \text { PubliclyHeldCurrency }}{\text { MonetaryBase }}=\frac{1+\lambda}{\alpha+\beta+\lambda}
$$

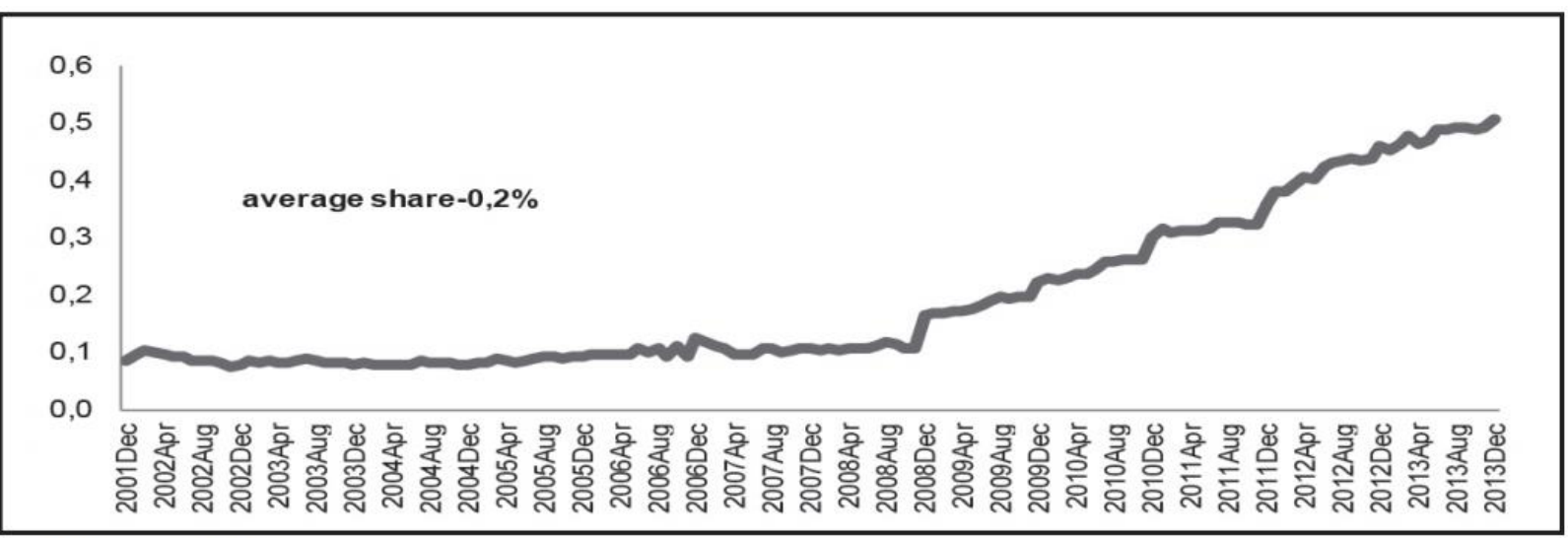

Source: $E C B$

Figure 3 Share of electronic money in circulation in the currency of circulation in the euro area[2] 
In this formula, $\alpha+\beta$ is Desired Reserve Ratio and $\lambda$ is Currency Drain Ratio. When the Currency Drain Ratio is relatively stable, the central bank can change the currency multiplier by increasing or decreasing the Desired Reserve Ratio to control the money supply of the entire society. However, the Desired Reserve Ratio is levied according to the currency level, and cash is not within the scope of the Desired Reserve Ratio collection. Figure 3 is the share of electronic money in circulation in currency of circulation in the euro area, in $\%$.[2]

As the proportion of electronic money in daily currency gradually increases, the electronic money blurs the boundaries between cash and deposits. Whether the electronic currency replaces cash or deposit, as can be seen from the above formula, the currency multiplier will become larger. Therefore, it will be difficult for the central bank to predict the country's currency multiplier and it will be difficult to control the money supply.

\subsubsection{The circulation of money will become faster}

The development of electronic money will have an impact on the speed of transaction circulation. According to Popovska-Kamnar, Neda [2], "With the use of e-money, transactions are relatively cheaper which allows increase in the number of transactions, and increase in the speed of money". Electronic money will change the proportion of the monetary base in the entire money stock to a certain extent. The following figure shows UK's M0 weight and velocity. Figure 4 shows that although M0 weights decreases, the velocity becomes much faster during the 1970-1998.

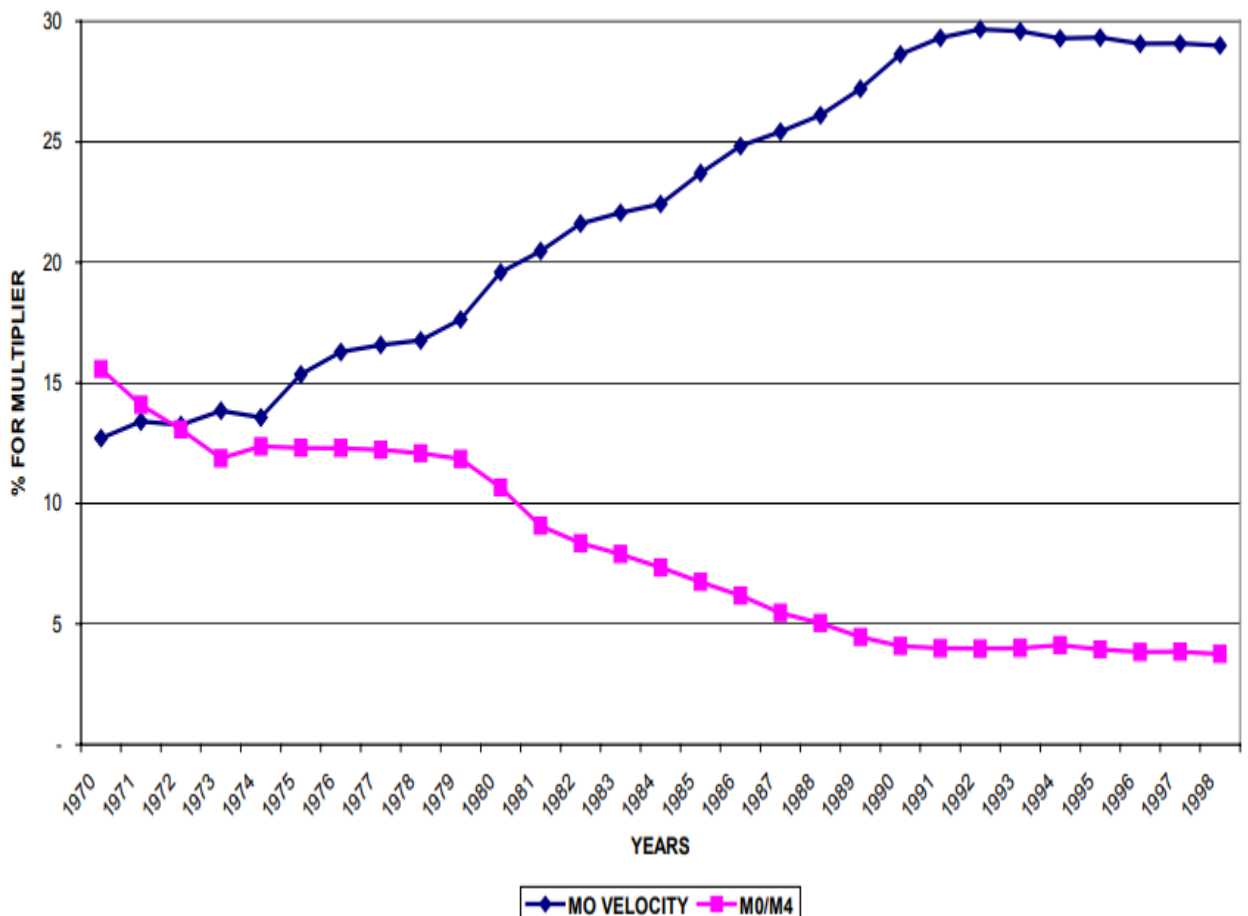

Figure 4 Velocity and M0 weight in money supply [7]

\subsubsection{Electronic money will decrease commercial banks' willingness to rediscount}

The discount rate refers to the price that commercial banks borrow money from the central bank. The central bank can control the money supply through the discount rate. The emergence of electronic money has led to a reduction in online banking operating costs, leading to intensified interest rate competition. Since the central bank has limited adjustments to the discount rate, commercial banks will reduce their willingness to borrow from the central bank in order to reduce financing and operating costs. The effect of the rediscount policy on the adjustment of the money supply under electronic money will become limited.

\section{SOLUTIONS}

\subsection{Reforming And Innovating the Existing Electronic Money Management Model}

So far, electronic money is still in the emerging stage of development, and the currency management system still has some defects. This requires reform and innovation of the existing system. First and foremost, it 
is important to standardize the issuance qualification certification system for electronic money. In the current electronic money market, there are many illegal issuers of electronic money. They will deceive consumers like counterfeit money, which will cause chaos in the market. In addition, establishing a reasonable development model is also an indispensable part. There are different electronic money development models in the contemporary world. One is to adopt the unified guidance of the central bank or the monetary authority and use the standardized and unified electronic money like Finland. The other model is to improve the legislation and offer a loose environment to encourage competitive development in the area such as the United States. Because this model can avoid the waste of resources caused by repeated investment and limit the development of competition. Each country should adopt an electronic money management and development model suitable for its national conditions, and actively innovate new models.

\subsection{Improving the Electronic Currency Supervision System And Supporting Laws}

The management of electronic money is inseparable from the mature legal system. First of all, strengthening the supervision of the main body of electronic currency issuance will help to reduce the impact of electronic money on the money supply mechanism. By supervising the main body of electronic currency issuance, the subjective initiative and flexibility of monetary policy can be mobilized to a great extent. Secondly, relevant financial institutions should strengthen the supervision of the electronic money industry and establish a unified electronic money payment network across the country. The government should provide payment infrastructure services and encourage equal competition to promote the formulation and implementation of e-money related standards, strengthen collaboration efficiency, formulate and promote system security protection standards. Meanwhile, ensuring the leadership role of the central bank not only helps the Banking Regulatory Commission to perform its supervisory functions but in special circumstances and it is beneficial to adjust the reserve ratio.

\section{CONCLUSION}

Electronic money is a new product of the information revolution and is still in the stage of emerging development. However, electronic money will play a greater role, and reaching higher heights is an inevitable result in the near future. However, electronic money will have some negative impacts on the central bank. Firstly, the central bank's currency issuance monopoly and independence will be threatened by electronic money. Secondly, Electronic money will have an impact on the central bank's mint tax revenue, which is a major source of income for the central bank. In addition, electronic money will also have an impact on the central bank's monetary policy. The substitution of electronic money for other currencies will have an impact on the currency multiplier and may cause the central bank to lose control of the money supply. Therefore, innovating the electronic money management model, strengthening the supervision system, and supporting related laws has become an urgent task for the healthy development of electronic money. A more complete development model also needs to be explored by various countries, thus making electronic money towards a direction conducive to financial stability and national economic development.

\section{ACKNOWLEDGMENT}

I want to express my most sincere gratitude to those who helped me throughout the process of completing this paper. First of all, I would like to thank Professor Sun of Johns Hopkins University for guiding my topic selection and my supervisor, Ms. Sun, for her help and feedback during the completion. This feedback has greatly contributed to the completion of my thesis. I am also very grateful to my family for their help and support throughout the process.

\section{REFERENCES}

[1] Electronic Money. European Central Bank Eurosystem statistics. 2020.

https://www.ecb.europa.eu/stats/money_credit_ban king/electronic_money/html/index.en.html

[2] Popovska-Kamnar, Neda. The use of electronic money and its impact on monetary policy.[J] Journal of Contemporary Economic and Business Issues 1.2. 2014: 79-92.

[3] Abrazhevich, Dennis. Classification and characteristics of electronic payment systems." International Conference on Electronic Commerce and Web Technologies. Springer, Berlin, Heidelberg, 2001.

[4] CPSS. Survey of developments in electronic money and internet and mobile payments. 2004.

[5] Buiter, Willem H. Seigniorage. No. w12919. National bureau of economic research, 2007, 1.

[6] European Central Bank, Issues arising from the emergence of electronic money, ECB Monthly Bulletin. November. 2000

[7] Gormez, Yuksel, and Christopher Houghton Budd. "Electronic money free banking and some implications for central banking." Central Bank Review 4.1. 2012: 67-105. 